\title{
PEDAGOGIAS CULTURAIS, HOMO ECONOMICUS E NEOLIBERALISMO: UMA PROPOSTA PARA PENSAR A EDUCAÇÃO CONTEMPORÂNEA
}

\author{
Paula Deporte de Andrade ${ }^{1}$ \\ Mozart Linhares da Silva ${ }^{2}$
}

\begin{abstract}
Resumo: Teorizações como as produzidas nos Estudos Culturais em Educação e nos Estudos Foucaultianos tem nos permitido compreender que as educabilidades contemporâneas são balizadas pelos ideais de governo presentes na nossa sociedade. Deste modo, nos valendo da articulação entre estas teorizações, objetivamos, neste texto, problematizar as pedagogias culturais como constituidoras dos sujeitos contemporâneos a partir do ethos do neoliberalismo. Para isso selecionamos como artefato cultural peças publicitárias veiculadas na Revista Veja durante os meses de junho e julho de 2017. A partir da análise percebemos que os anúncios analisados constituem exemplos de como os processos de educabilidade atuam na produção de subjetividades, regulando novas demandas de investimento no capital humano e exigindo que os sujeitos tornem-se empreendedores de si por meio de práticas permanentes de formação e aprendizado.
\end{abstract}

Palavras-chave: Pedagogias culturais; Empreendedor de si; Neoliberalismo

\begin{abstract}
Theorizations such as those produced in Cultural Studies in Education and Foucauldian Studies have allowed us to understand that contemporary educations are marked by the ideals of government present in our society. In this way, using the articulation between these theories, we aim, in this text, to problematize the cultural pedagogies as constitutive of the contemporary subjects from the ethos of neoliberalism. For this we selected as cultural artefact publicity published in Veja Magazine during the months of June and July 2017. From the analysis we consider that publicities analyzed are examples of how the processes of educability act in the production of subjectivities, regulating new demands of investment in human capital and requiring subjects to become entrepreneurs of themselves by means of permanent practices of formation and learning.

Key-words: Cultural pedagogies; Self-entrepreneur; Neoliberalism
\end{abstract}

\footnotetext{
${ }^{1}$ É licenciada em Pedagogia pela ULBRA de Cachoeira do Sul, mestre em Educação pela ULBRA de Canoas (área de concentração em Estudos Culturais) e Doutora em Educação pela Universidade Federal do Rio Grande do Sul (UFRGS) na linha de pesquisa Estudos Culturais em Educação. De junho a novembro de 2014 realizou doutorado sanduíche, com bolsa CAPES, na Universidade de Sydney. Recentemente realizou estágio de pós-doutorado na UNISC entre 2016-2017.

${ }^{2}$ Graduado, Mestre e Doutor em História pela PUCRS com extensão da Universidade de Coimbra. Pósdoutor em Educação, com ênfase em Estudos Culturais e Estudos Foucaultianos, pela UFRGS. Adjunto III da Universidade de Santa Cruz do Sul (UNISC), onde atua desde 1998. É professor-pesquisador no Programa de Pós-graduação em Educação (mestrado e doutorado) - PPGEDU -, onde atua como membro da Linha de Pesquisa Educação, Cultura e Produção de Sujeitos, e no Departamento de História e Geografia da UNISC.
} 


\section{Introdução}

O trabalho do pensamento não consiste em denunciar o mal que habitaria secretamente tudo o que existe, mas em pressentir o perigo que ameaça tudo o que é habitual e tornar problemático tudo o que é sólido (FOUCAULT, 2012, p. 612)

A compreensão de que, na contemporaneidade, diversos lugares - para além da escola - se propõem a educar e a produzir efeitos sob os modos como os sujeitos se constituem é uma premissa básica para aqueles que se dedicam a pensar a Educação. A partir do lugar em que nos inscrevemos, acreditamos que a aceitação de tal premissa se deve por muitos aspectos, mas destacamos aqui a importância das produções oriundas dos Estudos Culturais em Educação e dos Estudos Foucaultianos.

Destacamos os Estudos Culturais em Educação porque sabemos que um conjunto de pesquisadores associados a esta perspectiva (GIROUX, 1994; STEINBERG, 1997, ELLSWORTH, 2005, dentre muitos outros) se dedicaram a apontar em suas pesquisas a importância da cultura na constituição dos sujeitos. Ao fazerem isso, destacaram que espaços e produtos como museus, cinemas, revistas, sites, funcionam como artefatos culturais - pois são produzidos a partir da cultura que os circunscreve -, e são pedagógicos - já que, disseminam modos de ser e viver na cultura em que se está inserido.

Os Estudos Foucaultianos, por sua vez, tanto a partir dos escritos do pensador francês Michel Foucault quanto a partir dos escritos de seus comentadores, dedicados a relacionar as teorizações foucaultianas com o campo da Educação (como, por exemplo, LARROSA, 1994; RAMOS DO Ó, 2003; VARELA, 1994; VEIGA-NETO, 2007), nos ensinaram que variadas instituições atuam na constituição e regulação do sujeito. Logo, aprendemos a ser o que somos a partir de técnicas e estratégias de governo que conduzem nossas condutas a partir de determinado télos.

$\mathrm{Ou}$ seja, como destacamos rapidamente, ambas as teorizações nos permitem compreender que as educabilidades contemporâneas se dão de diferentes modos, sendo balizadas pelos ideais de governo presentes na nossa sociedade. Nesta direção, interessados em nos aprofundar neste tipo de discussão, apostamos na aproximação destes dois campos pela potente articulação teórica que temos a partir deste cruzamento. Isto é, nos valendo da possibilidade de pensar a educação para além da escola, especialmente a partir das noções de artefato cultural e pedagogias culturais, tão presentes nos Estudos Culturais, e da ideia 
de construção do empreendedorismo de si como modus vivendi, que Foucault chamou de homo economicus, objetivamos, neste texto, problematizar as pedagogias culturais como constituidoras dos sujeitos contemporâneos a partir do ethos do neoliberalismo. Para tanto organizamos este texto em três seções: na primeira, problematizamos as implicações das pedagogias nas artes de governo contemporâneas; na segunda, procuramos situar o ethos do neoliberalismo na contemporaneidade, sobretudo a partir dos contrastes possíveis com o liberalismo clássico; na terceira problematizamos os modos como as pedagogias culturais e suas estratégias de educabilidade, pautadas pelo ethos neoliberal, contribuem para a formação do homo economicus.

\section{Da pedagogia às pedagogias: a arte de governamento contemporâneo}

$\mathrm{Na}$ interseção entre o campo dos estudos culturais e o campo dos estudos foucaltianos entendemos a "ideia" de pedagogia como uma prática capaz de unir diversos elementos que, na sua racionalidade, produzem sentido e atuam na constituição dos sujeitos. Considera-se, nessa direção, a pedagogia como uma "ferramenta" que articula, em diferentes tempos históricos, regimes de verdade que constrangem os sujeitos a se inclinarem frente aos saberes e a sua própria "identidade". Noutras palavras, uma ferramenta que está implicada na produção dos sujeitos tal qual se podem perceber em determinados contextos históricos. Temos, portanto, nas problematizações atinentes à pedagogia, questões semelhantes com télos diverso. E é a esse télos que devemos nos mobilizar para problematizar as relações entre a constituição dos sujeitos e a pedagogia na História. A historiografia pedagógica é marcada por muitos exemplos disso: da Paidéia e a formação dos jovens gregos, inclinados ao governo da pólis na antiguidade clássica, ao corolário comeniano de "ensinar tudo a todos" na época barroca, ou mesmo a proposta de Kant para a pedagogia no século XVIII como alternativa para que os sujeitos chegassem às luzes e se tornassem autônomos e morais. Certamente, muitos outros exemplos na mesma linha poderiam ser apontados. Contudo, interessa-nos aqui salientar este traço da pedagogia, relacionado a uma "contínua vontade de investir e atuar sobre todos os aspectos e âmbitos da vida dos sujeitos" (CAMOZZATO e COSTA, 2013, p.23).

Considerando esta manifesta vontade de atuar sobre a vida dos sujeitos - que acompanha a pedagogia ao longo da história - é que problematizamos, na 
contemporaneidade, as múltiplas e fragmentadas possibilidades de condução da conduta oferecidas aos sujeitos não a partir de uma Pedagogia enquanto "reunião e ordenação de saberes educacionais, num corpo mais ou menos homogêneo e bem delimitado em relação aos outros saberes" (VEIGA-NETO, 2004, p.5), mas de pedagogias, o que nos abre a possibilidade de tensionarmos os saberes e práticas que envolvem o governamento ${ }^{3}$ de si e dos outros no mundo contemporâneo (CAMOZZATO, 2012). Portanto, não é à Pedagogia que direcionamos as lentes, mas às práticas pedagógicas disseminadas numa sociedade neoliberal marcada pelo descentramento dos sujeitos, fluidez, efemeridade, presenteísmo e pluralidade.

Esta proliferação de pedagogias implica no reconhecimento dos múltiplos processos de educabilidade que atravessam os sujeitos para além das tradicionais instituições educativas. Nos Estudos Culturais realizados no cotejo com a Educação, uma das possibilidades para se analisar estes processos formativos construídos de modos mais abrangentes, torna-se viável a partir do acionamento da ideia de pedagogias culturais. De acordo com Watkins, Noble e Driscoll "a noção de pedagogias culturais sinaliza a importância do pedagógico em outros reinos do que os da educação institucionalizada" (2015, p.1). Além de contribuir ao campo da Educação, chamando a atenção para o fato de que a educação na contemporaneidade se dá para além dos espaços institucionalizados e tradicionais, como escola, igreja e família, os autores ainda defendem que:

[...] pedagogias culturais é o melhor nome do presente para pensarmos sobre a diversidade de processos pedagógicos da vida porque este traz com ele, após décadas de trabalho em Estudos Culturais, um reconhecimento de que estruturas sociais e instituições nunca podem ser separadas das vidas comuns que as cercam, as informam e trazem as pessoas para agir nela. (WATKINS, NOBLE e DRISCOLL, 2015, p.17).

Nesta direção, interessados em problematizar as "novas" formas de subjetivação e constituição dos sujeitos a partir de processos mais amplos de governo e modulação de si, consideramos que o conceito de pedagogias culturais seja uma ferramenta analítica extremamente produtiva. Com isso, nosso interesse é analisar como, na sociedade contemporânea, o ethos da governamentalidade neoliberal é apreendido pelo sujeito e atua

\footnotetext{
${ }^{3}$ Veiga-Neto diferencia o termo governo, utilizado nos textos foucaltianos, de governamento para mostrar que o governo diz respeito à instituição de Estado enquanto governamento diz respeito às ações ou atos de governar “distribuídas microscopicamente pelo tecido social”. (VEIGA-NETO, 2007).
} 
na formação de sua subjetividade por meio das pedagogias culturais, colocadas em circulação pelos mais diferentes artefatos culturais. Vale lembrar, segundo Camozzato e Costa, que

A vontade de pedagogia integra a governamentalidade neoliberal como um traço dela e, efetivamente, investe sobre nós para que governemos a nós próprios e aos demais. Argumentamos que há vontade de pedagogia posto que há vontade de conduzir sujeitos, que há vontade de governar (2013, p.23. Grifos das autores)

Para situarmos as formas como as pedagogias culturais são acionadas na contemporaneidade consideramos necessário pensar também sobre o governo dos sujeitos a partir da perspectiva neoliberal. A análise, ainda que breve, do ethos neoliberal nos possibilita problematizar os atravessamentos das pedagogias culturais nos processos de subjetivação, o que implica considerar as formas como estas pedagogias mobilizam os dispositivos que agenciam a constituição do chamado homo economicus. Se a análise desse processo relacional do neoliberalismo e das pedagogias culturais não visa, necessariamente, uma proposta alternativa de constituição dos sujeitos na contemporaneidade, uma redenção pela educação, por exemplo, não podemos deixar de considerar que este tipo de problematização pode funcionar como um combustível, suscitando instrumentos diferentes que sejam "capazes de nos levar a compreender de outras maneiras o mundo em que vivemos para, a partir daí, ser possível criar novas formas de vida, novas maneiras de estar neste mundo" (VEIGA-NETO, 2000, s/p).

\section{Liberalismo \& neoliberalismo: problematizações}

Michel Foucault, no curso ministrado no Collège de France, de 1978-1979, publicado posteriormente com o título de Nascimento da Biopolítica (2008a), nos coloca frente a novas problematizações sobre o neoliberalismo. Na perspectiva do autor, o neoliberalismo não deve ser entendido como um universal a priori a partir do qual se pode estender as análises sobre o Estado e a sociedade. Ao contrário, na perspectiva de Foucault, é preciso tomá-lo em sua singularidade e fazê-lo funcionar como uma grade de inteligibilidade que possibilita problematizar a contemporaneidade, nomeadamente as estratégias de governamentalidade que incidem nos processos de subjetivação, sobretudo àqueles atinentes à educação e às pedagogias culturais, recorte deste artigo. 
É preciso tomar o neoliberalismo não apenas como um sistema econômico decorrente do clássico liberalismo, mas como uma "nova" forma de governamentalidade 4 que visa cobrir o tecido social por inteiro, ou seja, trata-se da constituição de um regulador de mercado geral da sociedade (FOUCAULT, 2008a, p. 199). No liberalismo "de" Adam Smith o corolário "laissez-faire" era a tônica da demanda que visava limitar a inferência do Estado na economia. Segundo Lagasnerie (2013, p. 46), "tratava-se de restringir a intervenção do Estado, de fixar-lhe certo número de limites a fim de reservar um espaço 'livre' em que pudessem vigorar, sem coerções externas, os mecanismos de mercado".

Ainda segundo o autor,

[...] o projeto neoliberal consiste em instituir uma verdadeira 'mercantilização' da sociedade. Para esses teóricos (do neoliberalismo), o objetivo é claro: é preciso construir uma nova sociedade em que a concorrência impere. A única forma social válida é o mercado $(2013,45)$.

E é justamente esta ideia de "disseminação" globalizante do mercado que impede que se estabeleça uma relação direta ou evolutiva entre liberalismo clássico e neoliberalismo, o que não significa dizer que não seja evidente, também, pontos em comum e continuidades. O liberalismo clássico e o neoliberalismo, segundo Lagasnerie, "promovem concepções distintas do mercado, de seu lugar na sociedade - e, o mais importante, da relação entre a racionalidade econômica e o Estado" (2013, p. 6). Se na perspectiva liberal o Estado era visto como um adversário que deveria ser constantemente enfrentado no intuito de limitar-lhe a interferência na economia, e era, nesse sentindo, um adversário da liberdade, um adversário que deveria ser combatido, na perspectiva neoliberal, ao contrário, o Estado é entendido como um aliado e até mesmo como um “instrumento". É nessa direção a afirmação de Veiga-Neto e Lopes, para quem "os

\footnotetext{
${ }^{4}$ O conceito de governamentalidade foi cunhado por Michel Foucault, em seu curso de 1978, no Collège de France, "Segurança, território, população". Com o conceito o autor quis apontar para uma nova grade de inteligibilidade do poder/razão de Estado que ocorre a partir do século XVI e efetiva-se a partir do século XVII com a anátomo-política do corpo da chamada sociedade disciplinar, mas que do século XVIII em diante, com o liberalismo, toma o corpo-espécie da população como cálculo das estratégias da gestão política, nominada de biopolítica. De modo geral, por governamentalidade Foucault entende "oconjunto constituído pelas instituições, procedimentos, análises e reflexões, cálculos e táticas que permitem exercer essa forma bem específica, bem complexa, de poder, que tem como alvo principal a população, como forma mais importante de saber, a economia política, como instrumento técnico essencial, os dispositivos de segurança. (...) enfim, por 'governamentalidade', acho que se deveria entender o processo, ou melhor, o resultado do processo pelo qual o Estado de Justiça da Idade Média, tornado nos séculos XV e XVI Estado Administrativo, encontrou-se, pouco a pouco, 'governamentalizado"' (2008b, p. 145).
} 
neoliberais o veem [Estado] como um aliado; ou, talvez melhor, como uma instância a seu serviço, ou seja, um servidor a serviço dos interesses do capital” (2011, p. 7).

Interessante notar como o ethos neoliberal passou a atuar como forja de uma sociedade hiper-individualizada, em que os sujeitos são produzidos a partir de processos de subjetivação que relacionam responsabilidade, liberdade e desejo como sustentação da autonomia individual em detrimento das cada vez mais abdicadas coletividades. Na análise de Bauman, no capitalismo contemporâneo estão a "derreter" os "elos que entrelaçam as escolhas individuais em projetos e ações coletivas - os padrões de comunicação e coordenação entre as políticas de vida conduzidas individualmente e, de um lado, e as ações políticas de coletividades humanas, de outro" (2001, p. 12). Estes elos que estabelecem relações de reciprocidade entre interesses individuais e coletivos cedem lugar à lógica da competitividade. Como lembra Lagasnerie,

Pois aquilo a que o neoliberalismo não cessou de se opor, aquilo contra o que ele se constituiu com mais força e persistência, é uma atitude filosófica mais geral (...) [que] tem sua origem no pensamento iluminista: tal atitude é a que consiste em promover uma percepção unificante ou unificadora da sociedade, valorizando tudo que diz respeito ao 'comum', ao 'coletivo', ao 'geral', em detrimento do que seria da esfera do individual, do particular, do local. (2013, p. 65-66)

É neste sentido que para os neoliberais, segundo Veiga-Neto, "a liberdade deve ser continuamente produzida e exercitada sob a forma de competição" (2011, p. 38). A competitividade intrínseca à dinâmica das relações sociais na contemporaneidade institui a lógica empresarial-corporativa como modus vivendi, cujo correlato é a "figura" do homo economicus. Conforme a descrição de Foucault, o homo economicus "é um empresário, e um empresário de si mesmo, sendo ele próprio seu capital, sendo para si mesmo seu produtor, sendo para si mesmo a fonte de [sua] renda" (2008a, p. 311). E como fonte de renda é necessário "cuidar de si" como um capital, fazer valer seu "capital humano", condição para a "produção" de sua própria satisfação no mundo do consumo e da competitividade. No entendimento dos teóricos neoliberais, conforme a análise de Foucault, o capital humano é composto de elementos inatos e adquiridos (2008a, p. 312). O primeiro nos leva ao campo da biologia, da hereditariedade e da gestão dos "bons" equipamentos genéticos dos indivíduos/população. O segundo tipo nos conduz à reflexão sobre a educação, o cuidado com a infância, a saúde, a dieta, a cultura familiar e, ainda, às 
formas como as pedagogias culturais podem atuar nos processos de subjetivação atinentes ao capital humano. Como mostra Foucault,

[...] os neoliberais observam que, na verdade, o que se deve chamar de investimento educacional, em todo caso os elemento que entram na constituição do capital humano, são muito mais amplos, muito mais numerosos do que o simples aprendizado escolar ou que o simples aprendizado profissional (2008a, p. 315).

Considerando estes atravessamentos que incidem no "capital humano" fica evidente que o neoliberalismo institui uma nova ou mais abrangente atuação do poder. Trata-se de um "sistema" em rede, flexível e culturalmente implicado, uma racionalidade que aciona as multiplas estratégias de governamento. É neste sentido a afirmação de Read: "Como uma forma de governamentalidade, o neoliberalismo parece paradoxalmente governar sem governar" $(2009, \text { p. } 27)^{5}$. E isto porque não é necessariamente o Estado que atua na produção de normalização e construção de comportamentos sociais e sim o próprio mercado, pois este age nos processos de subjetivação com grande eficiência fazendo com que o homo economicus se institua, conforme Hamann, como um "átomo" de interesse próprio, livre e autônomo, plenamente responsável por navegar pelo campo social utilizando cálculos de escolha racional e custo-benefício" (2012, p. 101). Na análise de Bauman sobre o individualismo na contemporaneidade, ele aponta que

o que costumava ser considerado uma tarefa para a razão humana, vista como dotação e propriedade coletiva da espécie humana, foi fragmentado ('individualizado'), atribuído às vísceras e energias individuais e deixado à administração dos indivíduos e seus recursos. (...) a ênfase (justamente com o que é importante, com o peso da responsabilidade) se transladou decisivamente para a auto-afirmação do indivíduo (2001, p. 38)

A sociedade individualizada é uma sociedade de indivíduos de sucesso ou falhos (losers). Vencedores vencem por seus próprios méritos, os que fracassam, não tiveram mérito suficiente. Não é sem sentido que experiências individuais sejam tão exploradas pela mídia: os casos de superação de adversidades por aqueles que, a primeiro olhar, estariam fadados ao fracasso, mas por suas próprias forças alcançaram o sucesso.

A relação direta entre um mundo de oportunidades que dependem das escolhas e decisões puramente individuais e os riscos que estas escolhas acarretam, nos remete à responsabilidade como um fardo que não pode ser compartilhado. Esta talvez tenha sido

\footnotetext{
${ }^{5}$ No original: "as a form of governmentality, neoliberalism would seem paradoxically to govern without governing”. Tradução livre dos autores.
} 
uma das estratégias mais "bem sucedidas" do neoliberalismo: "incutir valores de mercado em cada aspecto da vida social e de transferir a responsabilidade para o indivíduo (...)" (HAMANN, 2012, p. 105). E entre esses valores é preciso destacar a liberdade. Nesse sentido, para Veiga-Neto, "a governamentalidade neoliberal intervirá para maximizar a competição, para produzir liberdade para que todos possam estar no jogo econômico" (2011, p. 39).

Este novo "espírito" do capitalismo assentado na exacerbação da liberdade de escolha e competitividade não poderia ser adequado às rígidas regras que organizaram o “sistema" pelo menos até os anos 1970, cujo fordismo e taylorismo eram modelares. Pelbart aponta para a dinâmica do capitalismo e sua capacidade de incorporar a crítica, fazê-la, de certo modo, uma orientação para mudanças. Para o autor, "as reivindicações por mais autonomia, autenticidade, criatividade, liberdade, até mesmo a crítica à rigidez da hierarquia, da burocracia, da alienação nas relações e no trabalho, foi inteiramente incorporada pelo sistema" (2011, p. 96). Contudo, o que outrora era o objeto de crítica e reivindicações, agora é mobilizado e incorporado pelo próprio sistema. Como afirma Pelbart,

De repente os aspectos mais humanos do homem, seu potencial, sua criatividade, sua interioridade, seus afetos, tudo isso que ficava de fora do ciclo econômico produtivo, e dizia respeito antes ao ciclo reprodutivo, torna-se a matéria-prima do próprio capital, ou torna-se o seu próprio capital (2011, p. 99).

Não é sem sentido que "flexibilidade" é palavra-de-ordem do capitalismo pósfordista. Estar aberto a novas e finitas experiências e conexões produtivas, inovar, lançar mão da criatividade e autonomia são fundamentais num mundo de engajamentos temporários. Se o desejo de liberdade fora até então a bandeira reivindicatória frente a um sistema pesado e hierárquico, a partir dos anos 1980, com a emergência do capitalismo conexionista ou cognitivo, é justamente este desejo de liberdade que é capturado, mercantilizado e enquadrado pelo sistema (PELBART, 2011, p. 103).

Estas novas relações de trabalho implicam num redimensionamento da ideia de administração que, vale notar, vem sendo substituída pela gestão. Isso porque, conforme Veiga-Neto, "na modernidade líquida, já não se acredita ser possível administrar $o$ e para $o$ futuro, isso é, prever e garantir, com segurança, o futuro. Agora só parece ser possível fazer a gestão dos processos em um ambiente de incerteza" (2011, p. 44). Se a 
administração era uma ciência que visava organizar o futuro, a gestão procura dar conta do presente, de processos flexíveis e temporários.

Do ponto de vista dos comportamentos sociais, novas "ciências" se colocam a disposição de um público cada vez mais ávido por aconselhamento e motivação. Artefatos culturais como a caudalosa literatura de autoajuda, as técnicas de desenvolvimento humano, como o coaching e os receituários de sucesso são populares e compõem uma verdadeira cultura hedonista-individualista. Em análise sobre tema, Rüdinger aponta que nesta cultura individualista "o indivíduo precisa procurar dentro de si os recursos necessários para resolver suas dificuldades. Os problemas com que luta, embora se originem de fatores sociais, possuem uma natureza pessoal, que não tem nada a ver com a sociedade (1995, p. 18). É no mérito próprio, na superação de obstáculos e provações que o indivíduo assume a si como centralidade num processo em que as causas de seu virtual fracasso, de sua derrota frente a "candidatos melhor preparados" devem ser procuradas, também, “dentro de si".

A liberdade na "utopia" neoliberal não é um fim e sim um meio pelo qual os indivíduos fazem suas escolhas e satisfazem seus desejos sempre renovados, vale lembrar. Se no passado não muito tardio a liberdade fora o objeto das agendas políticas liberais e mesmo revolucionárias, não é fora de propósito que na contemporaneidade, garantidas as condições que equilibram as pulsões desejantes e a capacidade de ação para alcançá-los, ela se apresente, segundo observa Bauman, como "um slogan sem sentido, pois falta-lhe força motivacional” (2001, p. 24). Para o autor, “é essa virtual liberdade que assegura, em tempos líquidos, a ideia de que os homens e as mulheres são inteira e verdadeiramente livres, e assim a agenda da liberdade está praticamente esgotada” (2001, p. 30).

A construção desse mundo "mundo livre" mobiliza os dispositivos que acionam os processos de subjetivação, como é o caso da educação, ou de modo mais amplo, as pedagogias culturais. É preciso constituir sujeitos "sensíveis" a um mundo que não opera mais pela lógica de modelo ou "moldes" pré-configurados, mas na lógica modulatória, em que os fluxos educativos sejam constantes e permanentes. É Deleuze quem chama a atenção para esse deslocamento dos "moldes" para as "modulações", cuja materialidade pode ser exemplificada no deslocamento da fábrica para a empresa, do "exame" para o "controle" e, no caso que nos interessa efetivamente neste artigo, da escola para a “formação continuada". É neste sentido que, para o autor, "este é o meio mais garantido de 
entregar a escola à empresa" (1992, p. 221) ou ainda, considerando a sobrevida da escola, a “introdução da empresa em todos os níveis da escolaridade" (1992, p. 225). Olhar para as pedagogias culturais na contemporaneidade nos permite observar como são mobilizados os dispositivos de subjetivação que fazem os sujeitos livres, competitivos, responsáveis e economicamente viáveis.

\section{Pedagogias culturais, homo economicus e novas subjetividades/performatividades}

Acreditamos que a análise dos dispositivos de subjetivação a partir do conceito de pedagogias culturais nos permite compreender os processos que nos constituem sujeitos de determinados tipos por meio de diferentes relações e agenciamentos. Ainda que este tipo de investigação não seja suficiente para dar conta de todas as demandas e desdobramentos que permeiam a problemática da constituição do sujeito, consideramos, na esteira do pensamento de Veiga-Neto, que "saber como nos governam e como nos governamos é condição necessária para qualquer ação política que pretenda colocar minimamente sob suspeita aquilo que estão fazendo de nós e aquilo que nós estamos fazendo de nós mesmos" (2011, p.37).

Nesta direção, a percepção de que novos elementos e novos dispositivos de controle ajudam no refinamento das artes da governamentalidade neoliberal, permite $\mathrm{o}$ entendimento de que a produção de subjetividades não é mais privilégio da escola. Assim, se "os jovens e as crianças que estão na escola hoje transitam por muitos mundos" (VEIGA-NETO, 2011, p.49), eles devem - em cada mundo - ser incitados a aprender a aprender, a ser aprendizes permanentes, tornando-se empresários de si, transformando-se em capital humano a partir do viés neoliberal (id., p.51).

Para Costa, essa exigência para que o sujeito mobilize a seu favor a sua "potência de individuação" não é outra coisa "senão uma das expressões do exercício do que Foucault chama de governamentalidade neoliberal" (2009, p.180). Nesta configuração contemporânea de governo:

\footnotetext{
os indivíduos e as coletividades são cada vez mais investidos por novas tecnologias e mecanismos de governo que fazem de sua formação e de sua educação, num sentido amplo, uma espécie de competição desenfreada, cujo progresso se mede pelo acúmulo de pontos, como num esquema de milhagem. (COSTA, 2009, p.180-181)
} 
Ainda como destaca Costa, tais condições criam possibilidades para o aparecimento de tendências educativas, como a cultura do empreendedorismo e o ensino por competências. De qualquer modo, o que tais tendências pretendem reforçar é a necessidade de que o sujeito - para ser um bom capital humano - invista sobre si e incorpore o princípio do aprender a aprender, de modo que esta iniciativa priorize a individualidade ao invés do trabalho em grupo e que se volte, especialmente, para a inovação (ib., p.182).

Mas como estes princípios de mercado tornam-se princípios sociais? Como tais princípios são retratados nos artefatos culturais? De que modo as pedagogias culturais contemporâneas colaboram na produção de subjetividades pautadas pela ideia neoliberal de capital humano?

Esgotar tais perguntas, mesmo que fosse possível, não é o objetivo deste texto. Contudo, elas nos movem na direção de problematizarmos como os princípios de mercado atravessam a educação contemporânea. Ou, dito de outro modo, interessa-nos tensionar como o neoliberalismo produz representações que são aprendidas por aqueles que desejam ser indivíduos de sucesso. Diante disso, para analisarmos a produtividade destas representações nos artefatos culturais, optamos por trabalhar com anúncios publicitários veiculados em revista.

Escolhemos o artefato anúncios em revistas porque, como apontam estudiosos do gênero (como, por exemplo, MIRA, 2001; SCALZO, 2008; CARVALHO, 2010), para que as mesmas consigam manter-se no mercado editorial e ter um custo de produção que seja acessível ao leitor, a venda de espaço publicitário é essencial. Com isso podemos dizer que quanto mais lida uma revista é, mais efeitos os seus anúncios produzem. Cientes disso, interessa-nos analisar como tais anúncios colocam em evidência pedagogias culturais ligadas ao ethos neoliberal. Para termos uma amostragem mínima desta condição, elegemos como critério anúncios veiculados em revistas de grande expressividade e, por conta disso e da facilidade de acesso, optamos por anúncios veiculados na Veja, já que por meio do seu acervo digital é possível localizar o conjunto de edições que se deseja. Escolhida a Veja, aleatoriamente, escolhemos analisar anúncios veiculados nas edições referentes aos meses de junho e julho de 2017.

Interessa-nos analisar como o ethos neoliberal vem sendo veiculado nestes anúncios, que estratégias acionam, como produzem efeitos nos sujeitos.Trazer à cena alguns destes preceitos que, ao nosso ver, estão diretamente relacionados com as 
educabilidades contemporâneas é o nosso interesse a partir daqui. Comecemos pela ideia de empreendedorismo de si.

$\mathrm{Na}$ lógica daquilo que Foucault nomeou de governamentalidade neoliberal, os sujeitos "empreendedores de si" são os sujeitos do tipo ideal, capazes de agir sobre si e moldar sua subjetividade, tornando-se um sujeito com melhores condições de movimentarse com sucesso nesta fluída e ambivalente sociedade. Noutras palavras, é exigido dos sujeitos uma atitude performativa ${ }^{6}$, calcada no desempenho, eficiência e competitividade, atitude esta que alinha os processos de subjetivação à lógica corporativa.

As pedagogias culturais que atravessam o universo cultural contemporâneo nos oferecem inúmeros exemplos de práticas discursivas que produzem processos de subjetivação conduzidos por este ethos neoliberal que até aqui esboçamos.

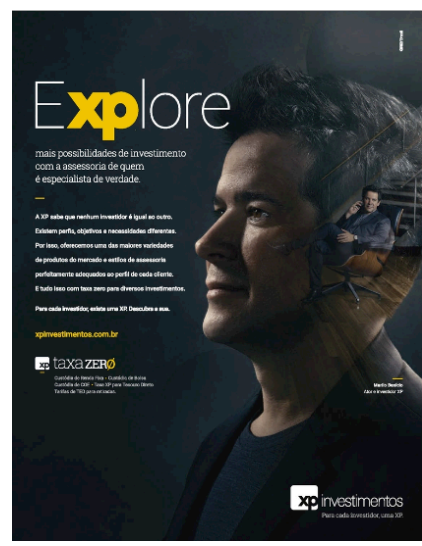

Edição 2533 - 07/06/2017 - p.25

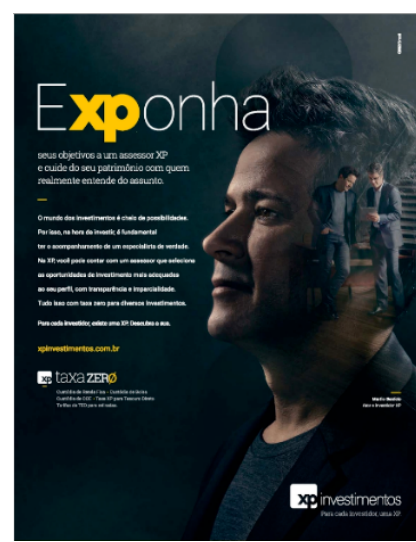

Edição 2535 - 21/06/2017 - p.07

Os anúncios acima não só vão ao encontro do ideal de sujeito empreendedor como se propõem a ensinar como ser um. Alicerçados na ideia de explorar e de expor, os textos dos anúncios destacam a importância de contar com especialista "de verdade" em consultoria de investimentos, de modo que o sujeito torne-se um investidor de sucesso baseado no seu perfil e nos seus interesses.

\footnotetext{
${ }^{6}$ Utilizamos aqui o conceito de performance forma livre, como comportamento, atuação e desempenho. Para uma discussão detalhada do conceito de performance ver: (HATTGE, 2014, Capítulo 4).
} 


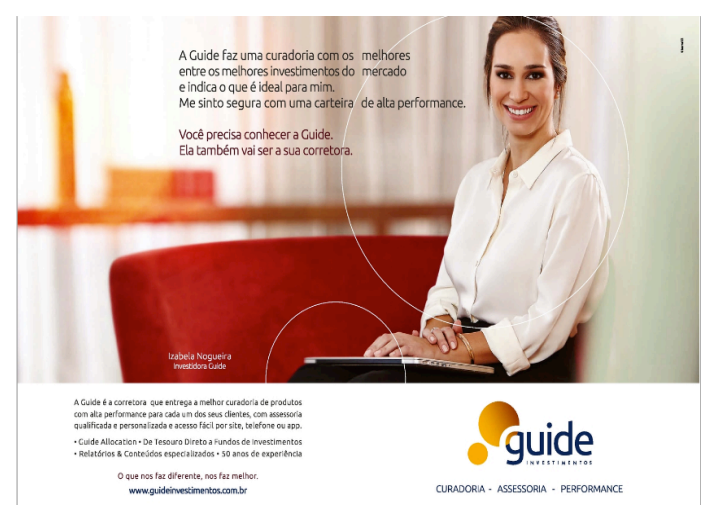

Edição 2534 - 14/06/2017 - p.16-17

Neste anúncio de duas páginas de outra empresa, a intenção é a mesma: legitimarse como a melhor opção para quem busca investir com segurança. Além da palavra segurança, destacamos as ideias de alta performance e assessoria qualificada. Considerando o momento econômico e político, vemos claramente que o discurso publicitário se vale do receio da população em aplicar em investimentos arriscados e tenta vender a ideia de que empresas sérias e estáveis são a melhor opção para quem quer empreender sem risco. Há aí um deslocamento de discurso, pois até pouco tempo atrás não era incomum chamadas do tipo "arrisque alto", "jogue pesado" e "empreenda sem medo". Ou seja, parece que o empreendedor do atual momento é um sujeito que investe, mas que antes estuda as possibilidades e procura alternativas que lhe ofereçam retorno mais seguro, o que, supostamente, justifica a importância de assessorias especializadas. Cientes deste perfil de clientes e extremamente alinhado com as exigências contemporâneas neoliberais, os bancos veiculam muitas publicidades, mas com discursos e estratégias semelhantes.

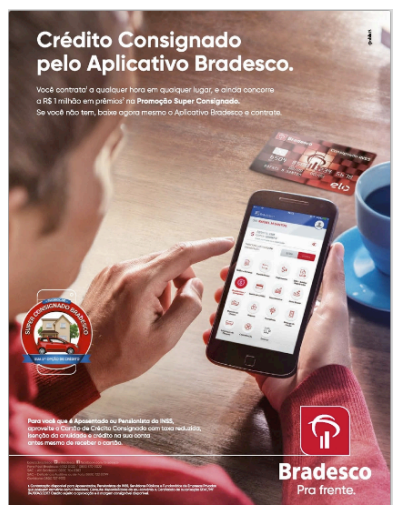

Edição 2533 - 07/06/2017 - p.116

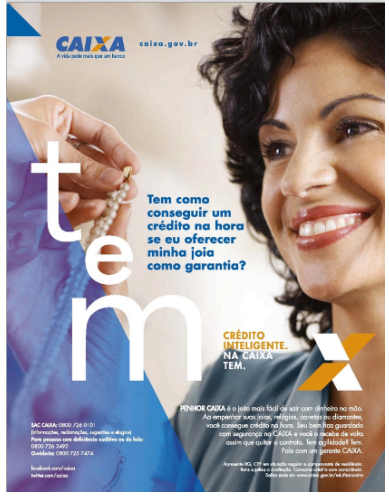

Edição 2540 - 26/07/2017 - p.14 
Um primeiro destaque fazemos para um conjunto de anúncios que operam a partir da lógica do estar em movimento. Com crise econômica ou não, realizando "ajustes" no caminho ou não, a mensagem parece ser "siga em frente". Atualize-se, reinvente-se, lance mão do que for possível - nem que seja penhorando ou fazendo empréstimo consignado-, mas esteja em movimento, faça a economia girar.

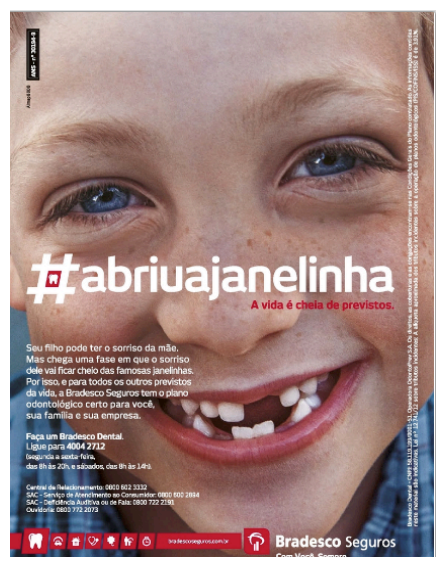

Edição 2538 - 12/07/2017 - p.100

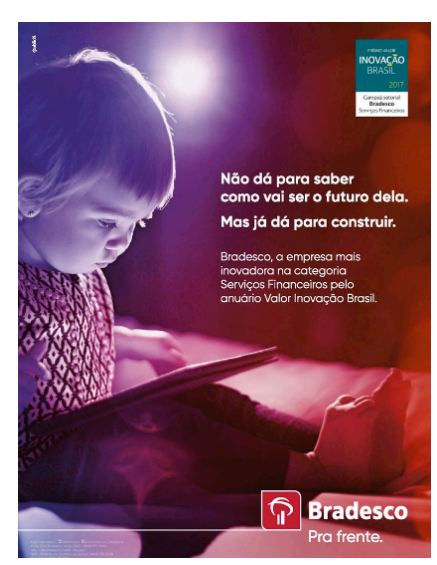

Edição 2536 - 28/06/2017 - p.08

Um segundo destaque diz respeito a questões que envolvem planejamento e construção do futuro. Há que ser aprendido que é responsabilidade dos pais garantir desde a mais tenra idade condições para que seus filhos, no futuro, sejam valorizados como bons capitais humanos. Assim, quanto antes os pais investirem nisso, maiores são as chances de êxito neste processo, pois estes sujeitos passam a adquirir uma vantagem competitiva que os qualifica para o mundo do trabalho. Para Bauman (2009) a vantagem competitiva “'depende cada vez mais de investimento em capital humano' e do conhecimento e das competências, tornando-se 'um potente motor para o crescimento econômico"' (p.676).

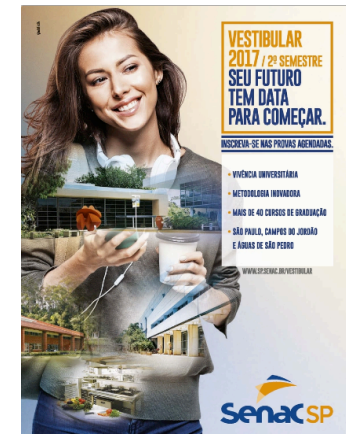

Edição 2540 - 26/07/2017 - p.08

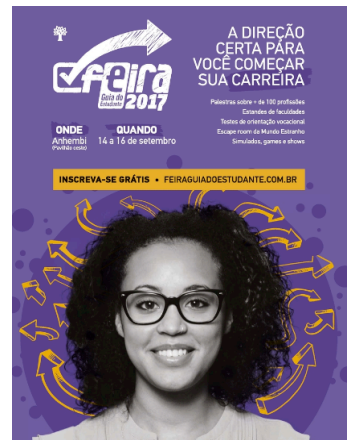

Edição 2540 - 26/07/2017 - p.56 
Os anúncios da Edição 2540 também nos mostram o quanto a questão do investimento sobre si, de modo que o próprio indivíduo agregue valor ao seu capital humano é importante na vida adulta também. Neste cenário a educação permanente é o recurso a ser acionado, especialmente por meio do consumo de cursos e faculdades, que supostamente, ajudam a colocar o futuro em operação e que dão a direção certa nas carreiras de cada um de nós. Nesta assertiva Lyotard, em 1979 [2009], já chamava a atenção para o gradual processo de mercantilização do saber profissional que tradicionalmente esteve a cargo das universidades. O que ele aponta é para um novo posicionamento da universidade que agora deve cumprir o papel de atender às demandas do mercado, norteadas, vale dizer, pelo utilitarismo e eficiência. Segundo Lyotard,

a questão, explícita ou não, apresentada pelo estudante profissionalizante, pelo Estado ou pela instituição de ensino superior não é mais: isto é verdadeiro? mas: para que serve isto? No contexto da mercantilização do saber, esta última questão significa comumente: isto é vendável? $\mathrm{E}$, no contexto do aumento do poder: isto é eficaz? (2009, p. 93).

A profissionalização está atrelada à formação continuada, o que conduz a um estreitamento entre a dinâmica exigida pela atualização constante das competências e desempenhos e os processos de subjetivação que atuam na constituição de sujeitos "aprendizes" e competitivos. Sobre esta lógica que tem o mercado como fim ou mesmo um ethos, Lyotard aponta que "a relação com o saber não é a da realização da vida do espírito ou da emancipação da humanidade; é dos utilizadores de um instrumental conceitual e material complexo e dos beneficiários de suas performances" (2009, p. 92).

$\mathrm{Na}$ era neoliberal é imprescindível que os sujeitos se constituam como aprendizes permanentes, que sejam aptos a escolher, investir e conduzir suas vidas individualizadamente, e que façam de seus méritos o relicário de sustentação de uma ética meritocrática. É necessário “obter qualidades para as quais já existe uma demanda de mercado, ou reciclar as que já se possui” (BAUMAN, 2008, p. 75) e, ainda, investir na vendabilidade de si. Na era neoliberal, portanto, é necessário constituir sujeitos que fazem de si seu empreendimento, sua humanidade em capital apto a atender as demandas do mercado.

Os anúncios analisados nos ensinam que não há fronteiras que não possamos ultrapassar, desde que adotemos uma postura coerente com o mundo da competitividade, mérito e empreendedorismo. A liberdade de decidir e optar num mundo de múltiplas e 
amplas escolhas é regulada pelo desejo. Em uma sociedade que se alimenta da fabricação de desejos a serem consumidos, empoderar o sujeito para que ele acredite que a satisfação dos mesmos é uma questão individual, desponta como uma potente estratégia para que o sujeito atue sobre si. Para Rose e Miller (2012) "a regulação da conduta torna-se uma questão do desejo de cada indivíduo de governar sua própria conduta livremente, no serviço da maximização de uma versão de sua felicidade e realização, as quais ele assume como próprias" (p.256).

Enfim, como objetivamos destacar, as peças publicitárias vêm funcionando como produtivas pedagogias culturais a serviço dos interesses neoliberais. Por meio deles os sujeitos aprendem que devem investir sobre si, que devem capacitar-se, tornar-se atrativos capitais humanos, planejar o futuro, procurar assessorias ou instituições dispostas a empreender junto, consumir conscientemente, entre muitos outros ensinamentos. Destacamos ainda que com isso não queremos dizer que os anúncios criam estes discursos, mas sim que eles os reforçam, os colocam em circulação, produzem efeitos na constituição do sujeito contemporâneo.

\section{Conclusão}

Os anúncios analisados constituem exemplos de como os processos de educabilidade atuam na produção de subjetividades, regulando condutas e performances de acordo com as novas demandas de investimento no capital humano. No ethos neoliberal, o empreendedorismo de si exige práticas permanentes de formação e aprendizado. Do homo discentis, imerso em processos educativos permanentes, dinâmico e inovador, exige-se que se constitua para uma sociedade de mudanças contínuas, preparado para uma vida de instabilidades. $\mathrm{Na}$ sociedade de aprendizagem, a educação não se restringe às modernas instituições fechadas, como as escolas, mas é investida inteiramente por dispositivos pedagogizantes, que atravessam todo o tecido social, atuando não apenas a partir do Estado, mas a partir de empresas, organizações e diversos locais, como a própria cidade e seus espaços de regulação de conduta. Na contemporaneidade, a educação, cujo prazo de validade é sempre anunciado, é permanente e constantemente renovada/inovada, o que faz com que os sujeitos invistam permanentemente em seu capital, condição para que não seja descartado como obsoleto. 


\section{Referências:}

BAUMAN, Zigmunt. Modernidade Líquida. Rio de Janeiro: Zahar, 2001.

. Vida para o consumo. Rio de Janeiro: Zahar, 2008.

. Desafios pedagógicos e modernidade líquida. Cadernos de Pesquisa, v.39, n.137, p.661-684, mai/ago 2009. (na versão online, p.1-24)

CARVAlHO, Nelly de. Publicidade: a linguagem da sedução. $3^{\mathrm{a}}$ ed. São Paulo: Ática, 2010.

CAMOZZATO, Viviane Castro. Da pedagogia às pedagogias - Formas, ênfases e transformações. Tese (Doutorado em Educação) - Programa de Pós-Graduação em Educação, Faculdade de Educação, Universidade Federal do Rio Grande do Sul, Porto Alegre, 2012.

; COSTA, Marisa Vorraber. Vontade de pedagogia - pluralização das pedagogias e condução de sujeitos. Cadernos de Educação. UFPel. n.44, jan-ab. 2013. Disponível em http://periodicos.ufpel.edu.br/ojs2/index.php/caduc/article/view/2737. Acesso 22 outubro de 2013. p. 22-44.

COSTA, Sylvio de Souza Gadelha. Governamentalidade Neoliberal, Teoria do Capital Humano e Empreendedorismo. Educação e Realidade.vol.34, p. 171-186, mai/ago 2009.

DELEUZE, Gilles. Conversações. Rio de Janeiro: Editora 34, 1992.

ELLSWORTH, Elizabeth. Places of learning: Media, architecture and pedagogy. New York: Routledge, 2005.

FOUCAULT, Michel. Estratégia, Poder - Saber - Col. Ditos \& Escritos IV - $3^{\text {a }}$ Ed. Forense Universitária: São Paulo, 2012.

. Nascimento da biopolítica: curso dado no Collège de France (1978-1979). São Paulo: Martins Fontes, 2008a.

. Segurança, Território, população: curso dado no Collège de France (1977-1978). São Paulo: Martins Fontes, 2008b, p. 145.

GIROUX, Henry. Doing Cultural Studies: Youth and the Challenge of Pedagogy. Harvard Educational Review 64:3 (Fall 1994), pp. 278-308.

http://www.henryagiroux.com/online articles/doing cultural.htm

HAMANN, Trent H. Neoliberalismo, governamentalidade e ética. Ecopolítica, 3: 99-133, 2012. Disponível em: <www.revistas.pucsp.br/ecopolitica $>$. Acesso em 15 de junho de 2017. 
HATTGE, Morgana Domênica. Performatividade e inclusão no Movimento Todos pela Educação. Tese de Doutorado. São Leopoldo: UNISINOS, 2014. Disponível em: http://www.repositorio.jesuita.org.br/bitstream/handle/UNISINOS/4347/07b.pdf?sequence $=1$. Acesso em 15/09/2017.

LAGASNERIE, Geoffroy de. A última lição de Michel Foucault. São Paulo: Três Estrelas, 2013.

LARROSA, Jorge. Tecnologias do eu e educação. In: SILVA, Tomaz Tadeu da (Org.). O sujeito da educação: estudos foucaultianos. Petrópolis: Vozes, 1994, p. 35-86.

LYOTARD, Jean-Fronçois. A condição pós-moderna. Rio de Janeiro: José Olympio, 2009.

MIRA, Maria Celeste. O leitor e a banca de revistas: a segmentação da cultura no século XX. São Paulo: Olho d'água/Fapesp, 2001.

NOGUERA-RAMÍREZ, Carlos Ernesto. O governamento pedagógico: da sociedade do ensino para a sociedade da aprendizagem. Tese (Doutorado em Educação) - Programa de Pós-Graduação em Educação, Faculdade de Educação, Universidade Federal do Rio Grande do Sul, Porto Alegre, 2009.

PELBART, Peter Pál. Vida capital: ensaios de biopolítica. São Paulo: Iluminuras, 2011.

RAMOS DO Ó, Jorge. O governo de si mesmo; Modernidade pedagógica e encenações disciplinares do aluno liceal (último quartel do século XIX - meados do século XX). Lisboa: Educa, 2003.

READ, Jason. A Genealogy of homo-economicus: Neoliberalism and the production of subjectivity. Foucault Studies, n. 6, p. 25-36, February 2009, p. 27. Disponível em: http://rauli.cbs.dk/index.php/foucault-studies/article/viewFile/2465/2463. Acesso em 15 de junho de 2017.

ROSE, Nikolas; MILLER, Peter. Governando o presente: gerenciamento da vida econômica, social e pessoal. Trad. Paulo Valério. São Paulo: Paulus, 2012.

RÜDIGER, Francisco. Literatura de auto-ajuda e individualismo. Porto Alegre: Editora da Ufrgs, 1996.

SCALZO, Marília. Jornalismo de Revista. $3^{\text {a }}$ ed. São Paulo: Contexto, 2008.

STEINBERG, Shirley R. Kindercultura: a construção da infância pelas grandes corporações. In: SILVA, Luiz Heron da; AZEVEDO, José Clóvis de; SANTOS, Edmilson Santos dos (Orgs.). Identidade Social e a Construção do Conhecimento. Porto Alegre: SMED, 1997. p.98-145. 
VARELA, Julia. O estatuto do saber pedagógico. In: SILVA, Tomaz Tadeu da (Org.). O sujeito da educação: estudos foucaultianos. Petrópolis: Vozes, 1994. p.87-96.

VEIGA-NETO, Alfredo. Michel Foucault e os Estudos Culturais. IN: COSTA, Marisa Vorraber (org.). Estudos culturais em educação: mídia, arquitetura, brinquedo, biologia, literatura, cinema... Porto Alegre: Ed. Universidade/UFRGS, 2000. Texto disponível em http://www.lite.fe.unicamp.br/cursos/nt/ta5.1.htm. Acesso em 16 de julho de 2017.

. Algumas raízes da Pedagogia moderna. In: ZORZO, Cacilda; SILVA, Lauraci D. \& POLENZ, Tamara (org.). Pedagogia em conexão. Canoas: Editora da ULBRA, 2004. Texto online. Disponível em http://michelfoucault.com.br/files/Algumas\%20Ra\%C3\%ADzes\%20da\%20Pedagogia $\% 20$ Moderna.pdf. Acesso em jun 2017.

. Governo ou governamento? Currículo sem Fronteiras. v.5, n.2, pp.79-85, Jul/Dez 2005. Disponível em: http://www.curriculosemfronteiras.org/vol5iss2articles/veiganeto.pdf. Acesso em 21/09/2017.

Foucault \& Educação. 2.ed. 1. reimp. Belo Horizonte: Autêntica, 2007.

. LOPES, Maura Corcini. Gubernamentalidad, biopolítica y inclusión. In: CORTEZSALCEDO, Ruth; MARÍN-DÍAZ, Dora (comp.). Gubernamentalidad y educación: discusiones contemporâneas. Bogotá: IDEP, 2011. p.105-122. Disponível em: http://www.michelfoucault.com.br/files/Governamentalidade, $\% 20$ biopol $\%$ C3\%ADtica $\% 2$ 0e\%20inclus\%C3\%A3o.pdf. Acesso em 15 de junho de 2017.

. Governamentalidades, neoliberalismo e educação. In: BRANCO, Guilherme Castelo e VEIGA-NETO, Alfredo. Foucault: filosofia \& política. Belo Horizonte: Autêntica, 2011, pp. 37-52

WATKINS, Megan, NOBLE, Greg, DRISCOLL Catherine (Org). Pedagogy: the undsaid of sociocultural theory. In: WATKINS, Megan, NOBLE, Greg, DRISCOLL Catherine. Cultural pedagogies and Human Conduct. London: Routledge, 2015. 